\title{
The Exploratory Factor Analysis of Zadrian-Ifdil Problem Checklist (ZIPC) High-School Version; An Alternative Assessment for Millenials Mental Health Conditions Mapping
}

\author{
Zadrian $\operatorname{Ardi}^{1^{*}}$, Ifdil Ifdil ${ }^{2}$ \\ 1,2Universitas Negeri Padang \\ *Corresponding author, e-mail: zadrian@fip.unp.ac.id
}

\begin{abstract}
Adolescents face various challenges and changes in order to realize their developmental tasks. The challenges are coupled with the technological disruption that requires adolescents to face new problems that have never existed before as millennials. However, the problems experienced by adolescents are often not expressed because of various obstacles, such as reluctance to tell spontaneously to the adults around them, high social conformity, so it is difficult to find help. For this reason, an alternative assessment is needed, which serves as an effort to map the problems experienced by adolescents and their mental health conditions accurately and actually. This study aims to find the value of the construct validity that forms the ZIPC to be used more widely and measure the actual problem conditions of the assessment subject. Participants involved in this study were 978 high school adolescents from all over Indonesia. The analysis used in finding the construct validity of this instrument is Exploratory Factor Analysis (EFA). The impact of changes and instrument conditions after analysis will be discussed.
\end{abstract}

Keywords: Assessment, Exploratory Factor Analysis, ZIPC, Mental Health

How to Cite: Ardi, Z., Ifdil, I. (2020). The Exploratory Factor Analysis of Zadrian-Ifdil Problem Checklist (ZIPC) High-School Version; An Alternative Assessment for Millenials Mental Health Conditions Mapping. International Journal of Research in Counseling and Education, 4 (2): pp. 117-127, DOI: http://doi.org/10.24036/00401za0002

\section{Introduction}

Mental health conditions tend to be dynamic when individuals are in the teenage period (Peltz, Rogge, Bodenlos, Kingery, \& Pigeon, 2020; Quan, Yang, \& Xia, 2020; Rehman, Bhuttah, \& You, 2020). This dynamic is in a context where adolescents can experience development in a positive direction or vice versa. Experience from the family, academic and social environment can also give an impression of the mental health conditions of adolescents, especially adolescents who are currently studying in high school. Adolescents tend to spend most of their time processing in academic and non-academic fields at school (Ardi, 2021; Ardi, Ifdil, \& Maysitoh, 2020).

Besides, adolescents are also faced with changes in the social environment and increasing demands compared to previous developmental periods and tasks (Rezaei \& Mousanezhad Jeddi, 2020; Tarescavage, Forner, \& Ben-Porath, 2020). As a period with the need for peer-group recognition and conformity, adolescents often spend more time in social relationships than the developmental period before and after adolescence. Mastery of this ability is also a task that adolescents must undertake and achieved before entering early adulthood (Basler \& Kriesi, 2019; Butterfield, Price, Woody, Morris, \& Silk, 2021; Stępień-Nycz, Bosacki, \& Białecka-Pikul, 2021). On the other hand, the ability to plan careers, economic management, fostering physical and personality conditions are also the focus that youth should have. The success of this period in various crucial aspects will have a positive impact on the next period of development (Ardi, 2017a, 2017b, 2019).

However, problems arise when adolescents are unable to make adjustments to changes that have occurred (Heradstveit et al., 2020; Jackson \& Bussey, 2020; Sugimura, Hihara, \& Hatano, 2020). This issue arises from adolescents' inability to fulfill various developmental tasks during adolescence, resulting in maladaptive behavior. Adolescents who are closed and difficult to communicate can have an impact on peer acceptance (Ardi, 2021; Ardi, Febriani, Ifdil, \& Afdal, 2019). The inability to develop physically through a series of activities 
often results in low self-esteem in adolescents. Other maladaptive behaviors can also appear in the form of anxiety in dealing with career planning and speaking in public and the like (Basu, Samanta, Basu, \& Bhattacharya, 2018; Davis, Dumas, Briley, \& Sussman, 2018). The complexity of adolescent's need to behave and act adaptively often raises problems with very high diversity. It can be seen from the variety of developmental tasks that must be fulfilled and accomplished by adolescents (Quan et al., 2020; Yankov, Davenport, \& Sherman, 2019).

Environmental changes, especially the disruption of technology in the last decade, have become new challenges for adolescents in maintaining their mental health conditions (Ardi \& Aulia, 2020; Ardi \& Putri, 2020). This issue is of particular concern to academics and mental health practitioners. Various cases in the past few years emerged from technological developments and their misuse (Daharnis \& Ardi, 2017). Cases such as cyberbullying, consumption of pornography, data theft, online fraud, and the like often make teenagers the target or even the object of the abuse itself-new issues related to technological disruption present new dimensions of problems that adolescents must face (Ardi, Neviyarni, \& Daharnis, 2019; Ardi \& Sukmawati, 2019; Sukmawati, Ardi, Ifdil, \& Zikra, 2019). The wide variety of problems from environmental changes and developmental tasks and the increasing challenges from technological changes make adolescents become individuals who should develop better (Ardi, Neviyarni, et al., 2019; Ardi \& Sisin, 2018; Ardi \& Sukmawati, 2018). On the contrary, cases that have emerged from technological developments present teenagers as perpetrators and victims.

With the characteristics of adolescents who tend to have high conformity with their peer groups, knowledge of the problems they face is a must for practitioners in psychology and counseling (Atalan Ergin \& Kapçi, 2019; Chierchia, Piera Pi-Sunyer, \& Blakemore, 2020; Jackson, Bussey, \& Myers, 2021). The knowledge of the problems directly impacts the interventions that practitioners can undertake in the field. Knowledge of the problems that arise in adolescents is one of the fundamental elements in intake assessment, which should be the starting point for mental health service interventions. Besides, issues of education, career, and family conditions often overlap. This is a challenge for mental health practitioners in schools (school counselors), especially when teenagers are reluctant to solve their problems.

The dynamic conditions and the varied problems of adolescents require a tool that can quickly reveal the actual conditions (Liang, Cao, Zhou, Li, \& Zhang, 2020; Macdonald et al., 2020; Sugimura et al., 2020). These expressing tools will make it easier to map the psychological conditions or mental health of today's adolescents. The instrument that is the basis for implementing this assessment should be able to accommodate all the dynamics and aspects of the problems previously discussed. With the characteristics of adolescents who are generally reluctant to tell their problems, especially to their parents or teachers, the presence of problemsolving instruments is a must in various educational institutions and mental health/counseling service providers (Kelleghan et al., 2019; Meisel \& Colder, 2020; Spiegler, Wölfer, \& Hewstone, 2019).

There are many measuring tools regarding the condition of adolescents, both complex and separate instruments (Fogaca, 2019; Ștefan, 2019; Tarescavage et al., 2020). However, with the characteristics of adolescents who are easily bored and do not care about their problems, it will be more effective if there are measuring instruments that can reveal adolescent problems more accurately and quickly (Kaya et al., 2019; Yankov et al., 2019). The Mooney Problem Checklist and Problem Unveiling Tool developed by Prayitno and the team are some of the common expression tools given to adolescents to find out the realm of the problems they face (Al-Hilawani, 2018; Jailani et al., 2020; Suranata, Rangka, \& Permana, 2020; Wibowo, Purwanto, \& Ramadhoni, 2020). However, the disclosure tools that have been developed previously are considered less practical in terms of time efficiency, measurement effectiveness, not relatable to the problems experienced by adolescents in the last decade. With these problems, it is essential to develop and update a reliable, practical, and proper expression tool to reveal the problems faced by adolescents.

The discussion of this research focuses on the development and validation of the Zadrian-Ifdil Problem Checklist (ZIPC) instrument, which has previously been through a trial process. This manuscript will present a study of Exploratory Factor Analysis (EFA) on all the attributes of adolescents' problems. This measuring instrument consists of a domain that has been compiled concerning the theory of development and existing measurement tools. The development of this measuring instrument should be used as a reference in conducting needs studies and mapping to provide counseling interventions and mental health services.

\section{Methods}

Participant

This study involved students from all regions in Indonesia with a random sampling process. The number of participants involved was 978 people, with $37.73 \%$ man and $62.27 \%$ woman. The distribution of the sample takes into account the representative sample in each province in Indonesia. This is done to get a good representative sample value so that it can be used more widely.

The sampling process considers regulations by requesting the consent of the target data and significant persons from adolescents (parents and teachers). Sampling was carried out within one week using the 
Surveymonkey.com platform with a one-vote one IP arrangement so that only one device could be used to populate the instrument.

Measurement

The instrument used in this study was an instrument that the team had previously developed to find the value of its construct validity, namely the Zadrian-Ifdil Problem Checklist (ZIPC). This measuring instrument in early development consisted of 62 items with nine factors forming students' daily problems. Along with further analysis involving input from experts in psychology, counseling, and assessment, 58 items were obtained and as many as nine factors, and three main clusters of measuring instruments.

The instrument's content is the result of an overview of the theory of adolescent development, self-theory, and existing instruments with modifications according to the needs of today's adolescents. The consideration of item arrangement and number of items also considers the possibility of processing time efficiency, content validity, objectivity, and reliability. The instruments for development included the Mooney Problem Checklist (Al-Hilawani, 2018; Jailani et al., 2020) and the Problem-Solving Tool (AUM) developed by Prayitno and his team (Ifdil et al., 2017; Ilyas et al., 2019). This research was conducted on this manuscript to test the condition of construct validity. Each cluster and the factors that make up the ZIPC are indeed appropriate in measuring the conditions that should be from the assessment target.

Data Analysis

Data analysis was carried out using Exploratory Factor Analysis (EFA) to find and identify the relationship between the manifest variable and the indicator variable that builds a construct, which in this case is the ZIPC disclosure instrument. Data processing in this study used Jeffreys's Amazing Statistics Program (JASP) Version 0.14 .1 , which is Open-Source.

\section{Results and Discussion}

The initial test to prove the validity and strength of the measuring instrument is to perform the Measure of Sampling Adequacy (MSA) test, which is tested simultaneously with the Kaiser-Meyer-Olkin (KMO) test and Bartlett's Test of Sphericity. The MSA test was conducted to determine the correlation between the initial variable formation, with an acceptable limit of 0.5.

Table 1. Results of the Measure of Sampling Adequacy (MSA) and Kaiser-Meyer-Olkin (KMO) Test

\begin{tabular}{cccccc}
\hline \multicolumn{2}{c}{ Cluster 1 } & \multicolumn{2}{c}{ Cluster 2 } & \multicolumn{2}{c}{ Cluster 3 } \\
Var & MSA & Var & MSA & Var & MSA \\
\hline PH1 & 0.862 & SO1 & 0.808 & ED1 & 0.762 \\
PH2 & 0.803 & SO2 & 0.843 & ED2 & 0.858 \\
PH3 & 0.763 & SO3 & 0.764 & ED3 & 0.831 \\
PH4 & 0.861 & SO4 & 0.814 & ED4 & 0.780 \\
PH5 & 0.768 & SO5 & 0.803 & ED5 & 0.692 \\
PH6 & 0.641 & SO6 & 0.769 & ED6 & 0.759 \\
PH7 & 0.840 & SO7 & 0.830 & ED7 & 0.847 \\
PH8 & 0.808 & SO8 & 0.804 & ED8 & 0.859 \\
PH9 & 0.615 & SO9 & 0.746 & EC1 & 0.771 \\
PS1 & 0.826 & FM1 & 0.720 & EC2 & 0.823 \\
PS2 & 0.803 & FM2 & 0.716 & EC3 & 0.831 \\
PS3 & 0.825 & FM3 & 0.708 & EC4 & 0.674 \\
PS4 & 0.816 & FM4 & 0.718 & EC5 & 0.698 \\
PS5 & 0.840 & FM5 & 0.716 & CA1 & 0.800 \\
PS6 & 0.768 & FM6 & 0.705 & CA2 & 0.810 \\
PS7 & 0.822 & FM7 & 0.736 & CA3 & 0.815 \\
PS8 & 0.739 & TM1 & 0.802 & CA4 & 0.870 \\
RG1 & 0.786 & TM2 & 0.799 & & \\
RG2 & 0.850 & TM3 & 0.843 & & \\
RG3 & 0.684 & & & & \\
RG4 & 0.715 & & & & \\
RG5 & 0.513 & & & & \\
Overall & 0.801 & Overall & 0.772 & Overall & \\
Time & & & & \\
Management (PH), Personal Issues (PS), Religious and Moral Issues (RG), Social Relations (SO), Family Issues (FM), & \\
& & & &
\end{tabular}

Based on Table 1, it can be interpreted that the variables tested from the Zadrian-Ifdil Problem Checklist (ZIPC) instrument are sufficient for further analysis. Even though there is one RG5 variable (the item "problematic because family members are not of the same religion") has an MSA value at the acceptance limit. 
Nevertheless, it is still acceptable for analysis. The analysis of MSA and KMO proves a strong correlation between the independent variables and the assumption that factor analysis is appropriate. The assessment of overall MSA acquisition on the KMO test shows a value above 0.5 for all clusters. The calculation shows that the strength and adequacy of the sample for analysis.

To determine the relationship between variables so that in the end, the collection will form a factor, the Bartlett Test is performed. Ideally, the collection of interrelated variables is a unit that shows the main factors that make up the construct of the measuring instrument. Based on Table 2, it is known that all clusters of measuring instruments have a significance value below 0.000 , so it can be interpreted that there is a good homogeneity of variants in the set of variables that make up the factors.

Tabel 2. Uji Bartlett dari Ketiga Cluster ZIPC

\begin{tabular}{lccc}
\hline & \multicolumn{3}{c}{ Bartlett's test } \\
& $\mathbf{X}^{\mathbf{2}}$ & $\mathbf{d f}$ & $\mathbf{p}$ \\
\hline Cluster 1 & 2772.244 & 231 & $<.001$ \\
Cluster 2 & 1853.088 & 171 & $<.001$ \\
Cluster 3 & 2735.434 & 136 & $<.001$ \\
\hline
\end{tabular}

Measurement of the developed measuring construct is then carried out in the form of an analysis of factor loading, principal components extraction, and varimax rotation. This analysis was carried out separately following the cluster group from predetermined measuring instruments. This calculation will produce a series of factor loading tables, eigenvalue values, path diagrams, and scree plots of each cluster being analyzed. The rotation of the factors used in this calculation is the varimax rotation, focusing on simplifying the factor matrix column, the ease of seeing the correlation between factors, eliminating clear factor loading values, and being able to differentiate factors better.

\section{Cluster 1: Physical, Personal Issues and Religion State}

As mentioned in the previous section, these measuring instruments are grouped into three main clusters. In this analysis, the construct conditions of measuring instruments that explain adolescents' physical, personal, and religion-state issues will be estimated. This analysis was conducted to see the grouping of each variable that identifies adolescent issues into more apparent factors so that it is easy to interpret the results later.

Based on Table 3, it can be understood that there is a correlation coefficient that shows the grouping of variables into three main factors and one factor that does not indicate any grouping (based on the results of the varimax rotation).

Table 3. Loading Factor of Cluster 1 Variables

\begin{tabular}{cccccc}
\hline & Factor 1 & Factor 2 & Factor 3 & Factor 4 & Uniqueness \\
\hline PH1 & 0.431 & & & & 0.777 \\
PH2 & 0.562 & & & 0.926 \\
PH3 & 0.482 & & & 0.909 \\
PH4 & 0.425 & & & 0.742 \\
PH5 & 0.553 & & & 0.756 \\
PH6 & 0.624 & & & 0.835 \\
PH7 & 0.584 & & & 0.585 \\
PH8 & 0.412 &. & & 0.803 \\
PH9 & 0.546 & & & 0.949 \\
PS1 & 0.449 & & & 0.611 \\
PS2 & & 0.661 & & 0.528 \\
PS3 & & 0.470 & & 0.733 \\
PS4 & & 0.545 & & 0.766 \\
PS5 & & 0.412 & & 0.777 \\
PS6 & & 0.552 & & 0.689 \\
PS7 & & 0.491 & 0.571 & 0.867 \\
PS8 & & & 0.407 & 0.743 \\
RG1 & & & 0.409 & 0.713 \\
RG2 & & & 0.633 & 0.573 \\
RG3 & & & 0.511 & 0.914 \\
RG4 & & & 0.451 & 0.994 \\
RG5 & & & & \\
\hline
\end{tabular}


The results of the calculations in Table 3 show that there is an agreement between the variables in one factor, which indicates that the set of variables is in the same construct. Physics 1 to 9 items are in the same factor with the correlation value that tends to be good, even though the PS1 variable ("often gloomy and feeling unhappy") belongs to this factor. The same case is also in the PS8 variable ("difficult to control sexual urge"), which is part of the religiousness and morality issues (RG) factor. Contextually, these variables correlate with religious values. However, in theory, sexual drive is more directed at individual personality, so it was decided to stay in the personality variable (PS).

Eigenvalue analysis is carried out to eliminate factors that form a construct of the measuring instrument being developed. As has been formulated from the theory of disclosure of adolescent mental health problems, in cluster 1 of the ZIPC, three main factors form a unity in measuring problems: groups of physical issues, personality issues, and religious issues and morality. The eigenvalue value shows the value $>1$. This result indicates the fulfillment of the requirements of the factor formation of the variables tested on the measuring instrument.

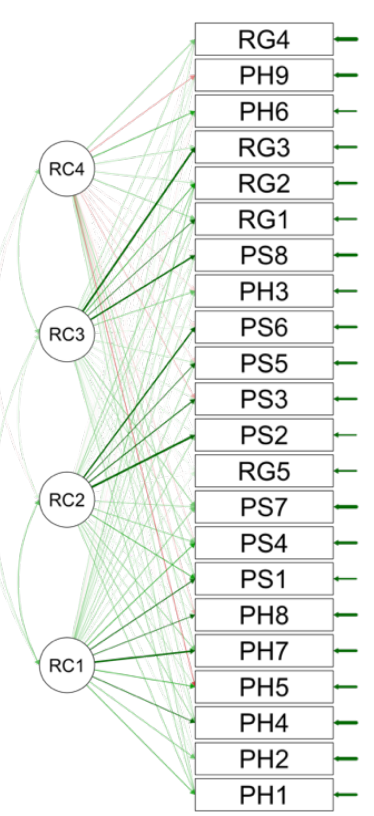

Fig 1. Path Diagram of Cluster 1

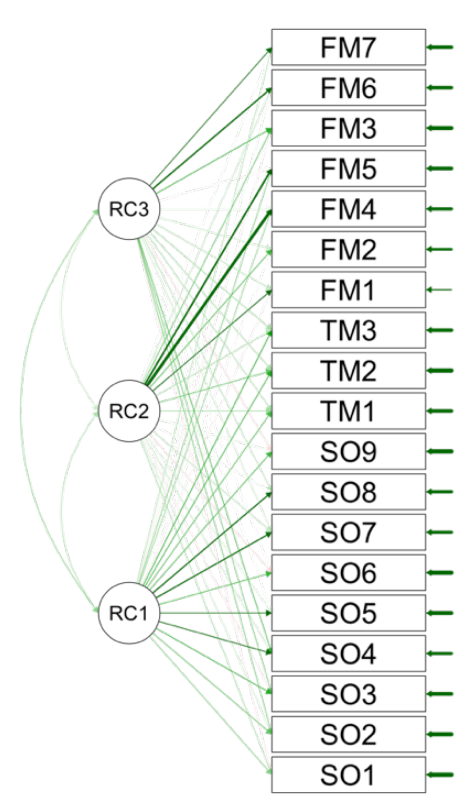

Fig 2. Path Diagram of Cluster 2

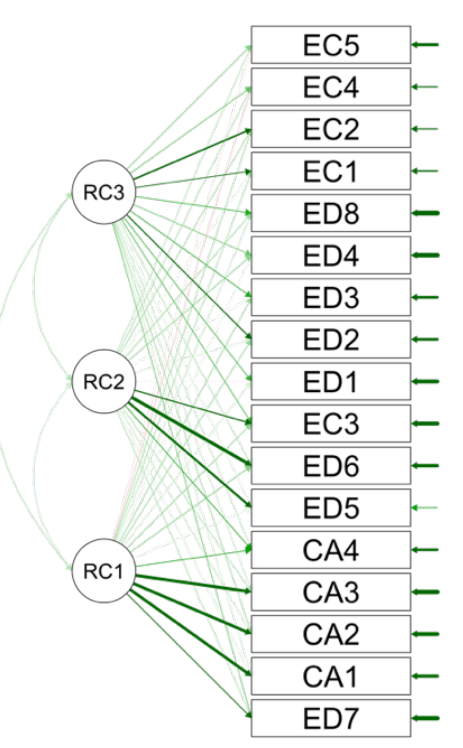

Fig 3. Path Diagram of Cluster 3 
Based on the calculations for Cluster 1, three factors can be explained by the eigenvalue. Factor 1 has an eigenvalue of 1.659 and can explain the variance of $7.5 \%$ of the construct it forms. In Factor 2, the eigenvalue is 1.613 , the value can explain the variance of $14.9 \%$ of the construct, while the third factor is the eigenvalue of 1.330 , which can explain the variance of $20.9 \%$. The fourth factor is not used/excluded because it does not meet the requirements

Table 4. Factor Characteristics of Cluster 1

\begin{tabular}{lccc}
\hline & Eigenvalues & Proportion var. & Cumulative \\
\hline Factor 1 & 1.659 & 0.075 & 0.075 \\
Factor 2 & 1.613 & 0.073 & 0.149 \\
Factor 3 & 1.330 & 0.060 & 0.209 \\
Factor 4 & 0.562 & 0.026 & 0.235 \\
\hline
\end{tabular}

The results of factor rotation testing in the form of a Scree Plot on instrument cluster 1 suggest that the feasible factor solution is three factors. In Scree Plot Cluster 1, it can be seen that between factor 1 to factor 3 , there is a striking difference, but at the time of rotation at factor 4, there is an insignificant difference. The three factors in Cluster 1 can be called Physical Issues (PH), Personal Issues (PS), and Religious-Moral Issues (RG). Changes occur in items that make up the Cluster 1 construct at ZIPC to require further testing through the Content Validity Ratio (CVR) and receiving input from experts.

\section{Cluster 2: Social Relations, Family Issues and Time Management}

In the second cluster, three factors compose social relations, family issues, and time management, as described in Tables 5 and 6 . The value of the factor loading coefficient on factor 1 shows the strength in the constructs of social relations issues, family issues, and time management. The coefficient value formed is stable above 0.4 . This indicates an intercorrelation between variables and factors.

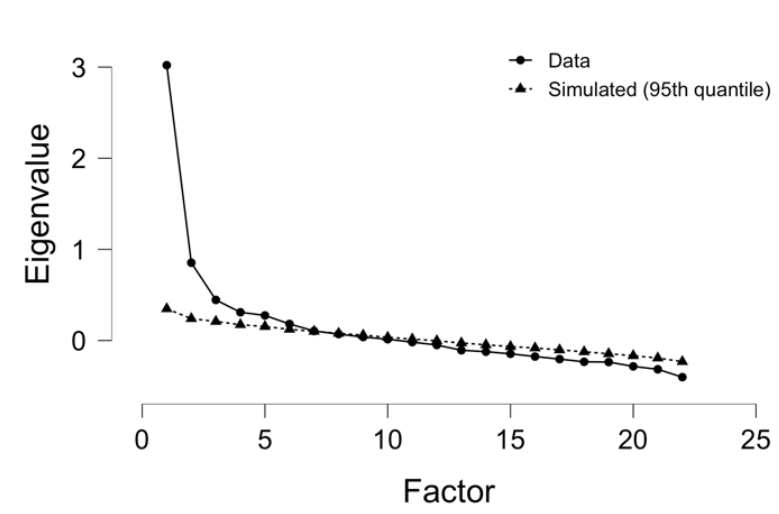

Fig.4 Scree Plot of Cluster 1

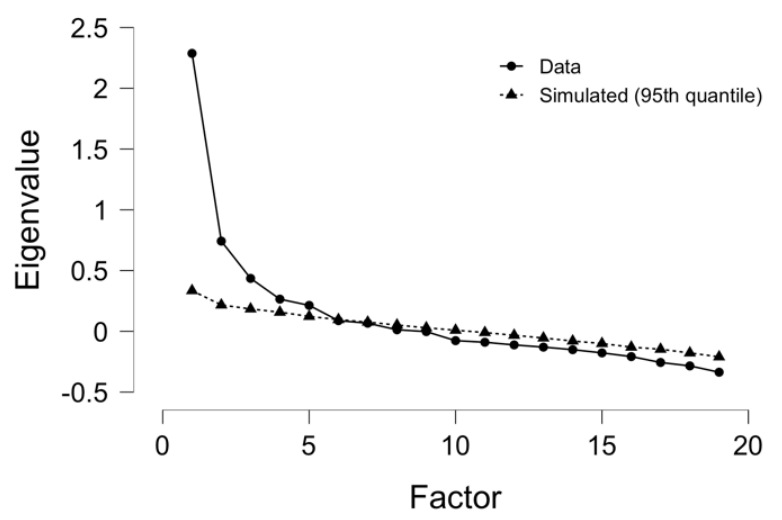

Fig 5. Scree Plot of Cluster 2

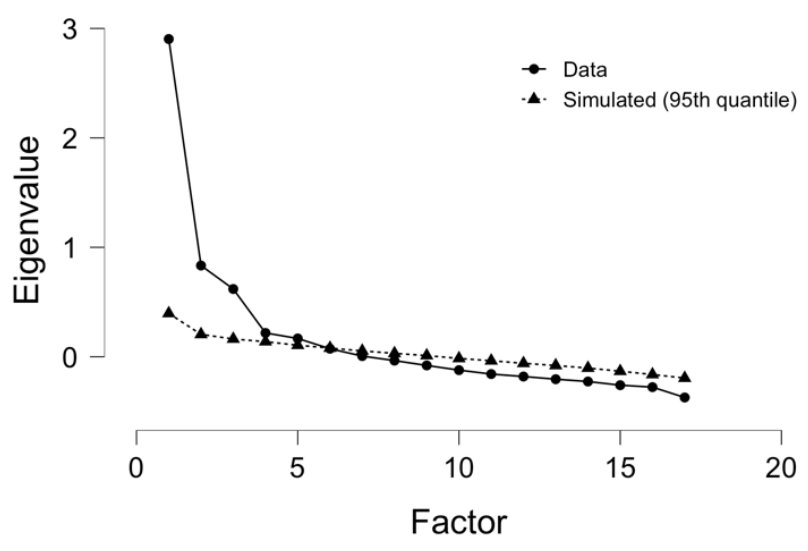

Fig 6. Scree Plot of Cluster 3 
The constructs formed in factor 1 are classified as social relations factors. The eigenvalue value formed on this factor is 1.661, the value means that the acceptance of the factor into a set of variables has been fulfilled. This factor can explain $8.7 \%$ of the variance. In the second factor, a collection of variables is formed, classified as family issues with an eigenvalue value of 1.316 , where this factor can explain $15.7 \%$ of the variance.

Table 5. Loading Factor of Cluster 2 Variables

\begin{tabular}{ccccc}
\hline & Factor 1 & Factor 2 & Factor 3 & Uniqueness \\
\hline SO1 & 0.545 & & & 0.935 \\
SO2 & 0.412 & & & 0.873 \\
SO3 & 0.490 & & & 0.821 \\
SO4 & 0.419 & & & 0.724 \\
SO5 & 0.403 & & & 0.834 \\
SO6 & 0.477 & & & 0.893 \\
SO7 & 0.469 & & & 0.760 \\
SO8 & 0.472 & & & 0.762 \\
SO9 & 0.439 & & & 0.896 \\
FM1 & & 0.424 & & 0.806 \\
FM2 & & 0.538 & & 0.898 \\
FM3 & & 0.673 & & 0.813 \\
FM4 & & 0.700 & & 0.473 \\
FM5 & & 0.548 & 0.502 & 0.654 \\
FM6 & & & 0.407 & 0.738 \\
FM7 & & & 0.431 & 0.819 \\
TM1 & & & 0.547 & 0.869 \\
TM2 & & & 0.423 & 0.815 \\
TM3 & & & & \\
\hline
\end{tabular}

The value at factor 3 represents the set of variables in time management with an eigenvalue of 0.848 and explains $20.1 \%$ of the variance. Even though the eigenvalue is at condition $<1$, the loading factor value shows the opposite value, where the correlation between variables and factors shows a reasonably good value.

Table 6. Factor Characteristics of Cluster 2

\begin{tabular}{cccc}
\hline & Eigenvalue & Proportion var. & Cumulative \\
\hline Factor 1 & 1.661 & 0.087 & 0.087 \\
Factor 2 & 1.316 & 0.069 & 0.157 \\
Factor 3 & 0.848 & 0.045 & 0.201 \\
\hline
\end{tabular}

The rotation results on the Scree Plot Cluster 2 also show the formation of 3 factors in this cluster. The decrease in the value of the Scree Plot Cluster 2 looks significant in factors 1 and 2 but not significant in factors 3 and 4 , so factor 4 is no longer considered a construct of the instrument. The results of this calculation are also seen in Figure 2, where there is a strong correlation coefficient value between the variables and the formed factors.

The calculation of rotation and the value of the eigenvalue factor in Cluster 2 proves that the constructs prepared to reveal the condition of adolescent mental health problems are following the initial preparation of the instrument. However, there are two items in FM6 and FM7 ("worried because the health of family members is disturbed" and "worried about not being able to meet the expectations of parents") that converge with factor 3. This condition requires further investigation, both through additional analysis for the item's condition, in the form of Content Validity Ratio (CVR) through expert judgment.

Cluster 3: Education (ED), Economic Issues (EC), Career (CA)

Cluster 3 shows the number of factors that are not too different from Clusters 1 and 2. The factors formed in the calculation of this exploratory analysis consist of education, economic issues, and career factors. The value of the factor loading coefficient at factor 1 shows the strength of the constructs that shape career problems. The loading factor value at factor 1 shows a coefficient value of more than 0.5 . This value indicates a good strength in the correlation between variables and factors. The eigenvalue value on factor 1 cluster 3 shows a coefficient of 1.992 and explains $11.7 \%$ of the variance. It can be concluded that factor 1 (Career) can predict the issues experienced by adolescents concerning their career and development. 
Table 7. Loading Factor of Cluster 3 Variables

\begin{tabular}{ccccc}
\hline & Factor 1 & Factor 2 & Factor 3 & Uniqueness \\
\hline ED1 & & & 0.421 & 0.891 \\
ED2 & & & 0.457 & 0.76 \\
ED3 & & & 0.536 & 0.841 \\
ED4 & & & 0.462 & 0.91 \\
ED5 & & & 0.608 & 0.626 \\
ED6 & & & 0.74 & 0.395 \\
ED7 & 0.422 & & & 0.742 \\
ED8 & & 0.325 & & 0.848 \\
EC1 & & 0.412 & & 0.81 \\
EC2 & & 0.523 & & 0.678 \\
EC3 & & 0.467 & & 0.656 \\
EC4 & & 0.479 & & 0.91 \\
EC5 & & 0.532 & & 0.944 \\
CA1 & 0.691 & & & 0.514 \\
CA2 & 0.698 & & & 0.479 \\
CA3 & 0.707 & & & 0.478 \\
CA4 & 0.692 & & & 0.695 \\
\hline
\end{tabular}

Factor 2 shows the strength in the constructs that form the economic issues factor. The strength of the correlation formed looks quite strong, so it can be stated that indeed the variables in this factor together form the economic issues factor. The eigenvalue of factor 2 shows the coefficient value of 1.442 with $20.2 \%$, which the variance can explain. The condition of factor rotation on the Scree Plot shows a somewhat unique condition, where points 1 and 2 show a significant decrease. In contrast, at factors 2 and 3 there is no significant decrease even though the eigenvalue factor 3 remains above 1 (1.389) with $28.4 \%$ which can be explained on the variance.

Table 8. Factor Characteristics of Cluster 3

\begin{tabular}{lccc}
\hline & Eigenvalue & Proportion var. & Cumulative \\
\hline Factor 1 & 1.992 & 0.117 & 0.117 \\
Factor 2 & 1.442 & 0.085 & 0.202 \\
Factor 3 & 1.389 & 0.082 & 0.284 \\
\hline
\end{tabular}

The results of the calculation of the three clusters that make up the ZIPC measuring instrument show the level of the construct's strength in expressing mental health conditions and problems experienced by adolescents as a whole. Each item that is developed has the power to the factors it compiles. This indicates that school counselors and mental health practitioners can conduct a mapping process on adolescent problems by administering this measuring instrument, especially those in high school.

The process of mapping youth problems can be carried out thoroughly and touches every aspect of their life regularly through ZIPC. The measurement results of the construct validity prove that this measuring instrument can robustly provide an overview of the nine elements of problems that students can experience, which are divided into three large clusters. The development of this measuring instrument is also a process of updating the previous measuring instrument, both in terms of content and the construct to be measured.

Consideration of each item, including the editorial of the following sentence, requires a more accurate analysis, such as CVR analysis or Rasch analysis. However, compared to the problem checklist instrument developed previously, ZIPC has met the requirements as a good measuring tool. Besides, ZIPC also relies on the practicality of measuring instruments, the efficiency of processing time, and the assessment target's psychological condition at the time of data collection. This also encourages further research to measure the effectiveness of the measuring instrument if it is followed by treatment after the measurement is carried out as an alternative in the pretest and basis in providing counseling interventions.

\section{Conclusion}

The Zadrian-Ifdil Problem Checklist (ZIPC) instrument is a renewal and innovation of a series of pre-existing problem checklist measuring tools. This development was carried out to increase the efficiency of processing time, the strength of items in revealing the assessment target problems, adjustments to the characteristics/demographics of the assessment targets. Besides, the instrument was developed by adjusting to new problems that emerged, especially in the era of the industrial revolution 4.0, and improving the 
functionality of the assessment results to be given follow-up in counseling intervention. Developments that involve large demographic diversity and expert judgment in terms of measuring instrument content require to construct analysis that compiles the measuring instrument itself. With this need, the calculation results presented in this manuscript answer the conditions of constructing the constructs of the items that have been developed to produce the factors of the measuring instrument. The analysis of the calculation results shows that the instrument can be concluded to have good construct validity and can be used as an alternative in mapping the problems or mental health conditions of adolescents, especially high-school students.

\section{References}

Al-Hilawani, Y. A. (2018). The quality of life of normal-achieving and low-achieving participants: Is it associated with IQ and metacognition? International Journal on Disability and Human Development, 172), 279293. Retrieved from https://www.scopus.com/inward/record.uri?eid=2-s2.085062766284\&partnerID=40\&md5=22bc13c6d105a40bc1c8f6efa53a6116

Ardi, Z. (2017a). Optimizing the Counselors' Role in Senior High School and Higher Education. Paper presented at the 9th International Conference for Science Educators and Teachers (ICSET 2017).

Ardi, Z. (2017b). Unsuitable Majoring: Does the Reorientation Would Help the Student for Revitalize Learning Activities? Paper presented at the 9th International Conference for Science Educators and Teachers (ICSET 2017).

Ardi, Z. (2019). An analysis of education principle implementation in an online counseling approach: a preliminary study based on analysis using the Rasch model. COUNS-EDU: The International Journal of Counseling and Education, 4(2), 59-68.

Ardi, Z. (2021). Controversy in Determining Criteria and Categories in Summarizing and Exploring The Research Data; Analysis of Assessment Procedures in The Social Science Research. Psychology and Education Journal, 58(1), 4109-4115.

Ardi, Z., \& Aulia, G. Z. (2020). The analysis of the parenting implications on the emotional closeness of parentchild improvement. Journal of Educational and Learning Studies, 3(2), 98-104.

Ardi, Z., Febriani, R. D., Ifdil, I., \& Afdal, A. (2019). Android "karirKu" Software Development for Exploration of Career Trends based on Personality Types. Paper presented at the Journal of Physics: Conference Series.

Ardi, Z., Ifdil, I., \& Maysitoh, M. (2020). Development and validation of the Zadrian-Ifdil Problem Checklist (ZIPC) for college students. International Journal of Technology, Innovation and Humanities, 1(1), 41-50.

Ardi, Z., Neviyarni, \& Daharnis. (2019). Konselo app: The future of distance counselling and therapy applications based on android technology. International Journal of Innovation, Creativity and Change, 5(6), 231244. Retrieved from https://www.scopus.com/inward/record.uri?eid=2-s2.085084436048\&partnerID=40\&md5=fa9c4d31b0195e977e60383f7350523c

Ardi, Z., \& Putri, S. A. (2020). The analysis of the social media impact on the millennial generation behavior and social interactions. Southeast Asian Journal of Technology and Science, 1(2), 70-77.

Ardi, Z., \& Sisin, M. (2018). The Contribution of Assertive Technique Behavioral Counseling to Minimize the Juvenile Delinquency Behavior. Jurnal Konseling Dan Pendidikan, 6(2), 67-77.

Ardi, Z., \& Sukmawati, I. (2018). Social Media and the Quality of Subjective Well-Being; Counseling Perspective in Digital Era.

Ardi, Z., \& Sukmawati, I. (2019). The Contribution of Social Media and Mobile Application to Individual Subjective Well-Being in Counseling Perspective. Journal of Counseling and Educational Technology, 2(1).

Atalan Ergin, D., \& Kapçi, E. G. (2019). Validity and reliability study of parental mediation for internet usage scale adolescent and parent forms in the Turkish sample. Journal of Measurement and Evaluation in Education and Psychology, 10(2), 117-132. doi:10.21031/epod.457218

Basler, A., \& Kriesi, I. (2019). Adolescents' development of occupational aspirations in a tracked and vocationoriented educational system. Journal of Vocational Behavior, 115. doi:10.1016/j.jvb.2019.103330

Basu, J., Samanta, M., Basu, S., \& Bhattacharya, M. (2018). Gender and mental health: Masculinity, femininity, modernity and daily hassles as predictors of subjective well-being. In Psychosocial Interventions for Health and Well-Being (pp. 313-333): Springer India.

Butterfield, R. D., Price, R. B., Woody, M. L., Morris, A. S., \& Silk, J. S. (2021). Adolescent girls' physiological reactivity to real-world peer feedback: A pilot study to validate a Peer Expressed Emotion task. Journal of experimental child psychology, 204. doi:10.1016/j.jecp.2020.105057 
Chierchia, G., Piera Pi-Sunyer, B., \& Blakemore, S. J. (2020). Prosocial Influence and Opportunistic Conformity in Adolescents and Young Adults. Psychological Science, 31(12), 1585-1601. doi:10.1177/0956797620957625

Daharnis, D., \& Ardi, Z. (2017). The Use of" Psychological Tests" for Early Childhood. Paper presented at the International Conference of Early Childhood Education (ICECE 2017).

Davis, J. P., Dumas, T. M., Briley, D. A., \& Sussman, S. (2018). A meta-analysis of the association between substance use and emerging adult development using the IDEA scale. American Journal on Addictions, 273), 166-176. doi:10.1111/ajad.12707

Fogaca, J. L. (2019). Combining Mental Health and Performance Interventions: Coping and Social Support for Student-Athletes. Journal of Applied Sport Psychology. doi:10.1080/10413200.2019.1648326

Heradstveit, O., Gjertsen, N., Iversen, A. C., Aasen Nilsen, S., Gärtner Askeland, K., Christiansen, Ø., \& Hysing, M. (2020). Substance-related problems among adolescents in child welfare services: A comparison between individuals receiving in-home services and those in foster care. Children and Youth Services Review, 118. doi:10.1016/j.childyouth.2020.105344

Ifdil, I., Ilyas, A., Churnia, E., Erwinda, L., Zola, N., Fadli, R. P., . . . Refnadi, R. (2017). Pengolahan Alat Ungkap Masalah (AUM) dengan Menggunakan Komputer Bagi Konselor. Jurnal Aplikasi IPTEK Indonesia, 1(1), 17-24.

Ilyas, A., Ifdil, I., Ardi, Z., Fadli, R. P., Erwinda, L., Churnia, E., . . Suranata, K. (2019, 2018). Validation of AUM software: A counselor tool for analyse human problems on counseling and educational practice.

Jackson, E. F., \& Bussey, K. (2020). Under Pressure: Differentiating Adolescents' Expectations Regarding Stereotypic Masculine and Feminine Behavior. Sex Roles, 83(5-6), 303-314. doi:10.1007/s11199-01901113-0

Jackson, E. F., Bussey, K., \& Myers, E. (2021). Encouraging Gender Conformity or Sanctioning Nonconformity? Felt Pressure from Parents, Peers, and the Self. Journal of Youth and Adolescence, 5044), 613-627. doi:10.1007/s10964-020-01387-8

Jailani, O., Adli, A. H. T., Amat, M. A. C., Othman, S. M., Deylami, N., \& Rahim, N. S. A. (2020). The Self-Perceived Problems among Malaysian Pre-university Students: Implications for College Counselling. Asian Journal of University Education, 16(3), 112-124. doi:10.24191/ajue.v16i3.11075

Kaya, C., Umucu, E., Rumrill, P., Chan, F., Muller, V., Bezyak, J., \& Iwanaga, K. (2019). Psychometric Validation of a Turkish Version of the Inventory of Common Problems: a Tool for Turkish College Counselors. International Journal for the Advancement of Counselling, 41(3), 436-448. doi:10.1007/s10447-0189360-0

Kelleghan, A., Mali, L., Malamut, S., Badaly, D., Duong, M., \& Schwartz, D. (2019). Cross-Ethnic Friendships, Intergroup Attitudes, Intragroup Social Costs, and Depressive Symptoms among Asian-American and Latino-American Youth. Journal of Youth and Adolescence, 48(11), 2165-2178. doi:10.1007/s10964019-01143-7

Liang, Y., Cao, H., Zhou, N., Li, J., \& Zhang, L. (2020). Early home learning environment predicts early adolescents' adjustment through cognitive abilities in middle childhood. Journal of Family Psychology, 34(8), 905917. doi:10.1037/fam0000675

Macdonald, J. A., Greenwood, C., Letcher, P., Spry, E. A., McAnally, H. M., Thomson, K., . . Olsson, C. A. (2020). From adolescence to parenthood: a multi-decade study of preconception mental health problems and postpartum parent-infant bonds. Social Psychiatry and Psychiatric Epidemiology. doi:10.1007/s00127-020-01965-y

Meisel, S. N., \& Colder, C. R. (2020). An examination of the joint effects of adolescent interpersonal styles and parenting styles on substance use. Development and Psychopathology. doi:10.1017/S0954579420001637

Peltz, J. S., Rogge, R. D., Bodenlos, J. S., Kingery, J. N., \& Pigeon, W. R. (2020). Changes in psychological inflexibility as a potential mediator of longitudinal links between college students' sleep problems and depressive symptoms. Journal of Contextual Behavioral Science, 15, 110-122. doi:10.1016/j.jcbs.2019.12.003

Quan, F., Yang, R., \& Xia, L. X. (2020). The longitudinal relationships among agreeableness, anger rumination, and aggression. Current Psychology. doi:10.1007/s12144-020-01030-6

Rehman, A. U., Bhuttah, T. M., \& You, X. (2020). Linking burnout to psychological well-being: The mediating role of social support and learning motivation. Psychology Research and Behavior Management, 13, 545-554. doi:10.2147/PRBM.S250961 
Rezaei, A., \& Mousanezhad Jeddi, E. (2020). Relationship between wisdom, perceived control of internal states, perceived stress, social intelligence, information processing styles and life satisfaction among college students. Current Psychology, 39(3), 927-933. doi:10.1007/s12144-018-9804-z

Spiegler, O., Wölfer, R., \& Hewstone, M. (2019). Dual Identity Development and Adjustment in Muslim Minority Adolescents. Journal of Youth and Adolescence, 48(10), 1924-1937. doi:10.1007/s10964-019-011179

Ștefan, C. A. (2019). Self-compassion as mediator between coping and social anxiety in late adolescence: A longitudinal analysis. Journal of Adolescence, 76, 120-128. doi:10.1016/j.adolescence.2019.08.013

Stępień-Nycz, M., Bosacki, S., \& Białecka-Pikul, M. (2021). Theory of Mind in Adolescence: Developmental Change and Gender Differences. JOURNAL OF EARLY ADOLESCENCE, 41(3), 424-436. doi:10.1177/0272431620919164

Sugimura, K., Hihara, S., \& Hatano, K. (2020). Emotional separation, parental trust, and psychosocial adjustment in preadolescence and early adolescence. Journal of Adolescence, 84, 165-170. doi:10.1016/j.adolescence.2020.09.001

Sukmawati, I., Ardi, Z., Ifdil, I., \& Zikra, Z. (2019). Development and Validation of Acceptability of Mental-Health Mobile App Survey (AMMS) for Android-based Online Counseling Service Assessment. Paper presented at the Journal of Physics: Conference Series.

Suranata, K., Rangka, I. B., \& Permana, A. A. J. (2020). The comparative effect of internet-based cognitive behavioral counseling versus face to face cognitive behavioral counseling in terms of student's resilience. Cogent Psychology, オ1). doi:10.1080/23311908.2020.1751022

Tarescavage, A. M., Forner, E. H., \& Ben-Porath, Y. (2020). Construct Validity of DSM-5 Level 2 Assessments (PROMIS Depression, Anxiety, and Anger): Evidence From the MMPI-2-RF. Assessment. doi:10.1177/1073191120911092

Wibowo, M. E., Purwanto, E., \& Ramadhoni, S. R. (2020). Exploring empathy among eastern, central, and western Indonesia counseling students. International Journal of Scientific and Technology Research, 9(2), 131-133. Retrieved from https://www.scopus.com/inward/record.uri?eid=2-s2.085079670017\&partnerID=40\&md5=d066134a5f72e6bd914cac2797dfe93c

Yankov, G. P., Davenport, N., \& Sherman, R. A. (2019). Locating mental toughness in factor models of personality. Personality and Individual Differences, 151. doi:10.1016/j.paid.2019.109532 